\title{
Mushroom ethanolic extracts as cosmeceuticals ingredients: Safety and ex vivo skin permeation studies
}

\author{
Oludemi Taofiq ${ }^{\mathrm{a}, \mathrm{b}, \mathrm{c}}$, Francisca Rodrigues ${ }^{\mathrm{d}}$, Lillian Barros ${ }^{\mathrm{a}}$, Maria F. Barreiro ${ }^{\mathrm{a}, \mathrm{c}}$, \\ Isabel C.F.R. Ferreira ${ }^{\mathrm{a}, *}$, M. Beatriz P.P. Oliveira ${ }^{\mathrm{d}}$ \\ ${ }^{a}$ Centro de Investigação de Montanha (CIMO), Instituto Politécnico de Bragança, Campus de Santa Apolónia, 5300-253, Bragança, Portugal \\ ${ }^{\mathrm{b}}$ GIP- USAL, Unidad de Nutrición y Bromatología, Faculty of Pharmacy, University of Salamanca, Campus Miguel de Unamuno, 37007, Salamanca, Spain \\ ${ }^{\mathrm{c}}$ Laboratory of Separation and Reaction Engineering (LSRE), Associate Laboratory LSRE/LCM, Polytechnic Institute of Bragança, Campus de Santa Apolónia, 1134, 5301- \\ 857, Bragança, Portugal \\ ${ }^{\mathrm{d}}$ REQUIMTE/LAQV, Department of Chemical Sciences, Faculty of Pharmacy, University of Porto, Porto, Portugal
}

A R T I C L E I N F O

\section{Keywords:}

Mushrooms

Bioactive compounds

Cosmeceuticals

Cytotoxicity

Skin permeation

\begin{abstract}
A B S T R A C T
Mushrooms are important sources of natural bioactive compounds that are increasingly used as cosmeceutical ingredients. In this context, ethanolic extracts were prepared from Ganoderma lucidum and Pleurotus ostreatus and tested by incorporation into base cosmetic creams. In vitro safety evaluation of the extracts and cosmetic formulations prepared therefore was carried out using the MTT and LDH assays in keratinocyte (HaCaT) and fibroblast (HFF-1) cell lines. Moreover, they were submitted to ex vivo skin permeation studies using a Franz diffusion apparatus with pig ear skin as permeation membrane. The results showed the absence of toxicity for keratinocytes and fibroblasts in a concentration dependent manner, which is indicative of the safety of these extracts for cosmeceutical ingredients purposes. Protocatechuic and syringic acids were the only compounds permeating from $G$. lucidum extract in the first $8 \mathrm{~h}$ of study, no penetration was observed for phenolic acids found in $P$. ostreatus extract and formulation. These results pointed out for the suitability of using mushroom extracts as skin care ingredients and may contribute for the valorisation of wastes generated by the mushroom processing industry, which can serve as raw-materials for the obtainment of the extracts.
\end{abstract}

\section{Introduction}

The skin is the largest organ of the human body accounting for about $15 \%$ of the total body weight, acting as a barrier between the internal and the external environment and providing protection against foreign bodies (Kamble et al., 2017). Extracellular matrix (ECM) of the skin is the structural support network made up of diverse proteins, sugars and other components. Some of these structural components include collagen, elastin, fibronectin, laminin and tenascin hyaluronic acid. Collectively, these compounds are responsible for maintaining the tensile strength, cell adhesion, cell migration and wound healing of the skin (Kular et al., 2014).

Skin care products are generally applied to exert a positive effect on skin hydration and stabilization of the epidermal barrier. To respond to a continuous demand for product diversification, the global cosmetic market needs to grow continuously, resulting in the emergence of products with different claims and functional properties (Taofiq et al., 2018, 2016a). Moreover, the rising consumer's consciousness and awareness about the origin, safety and environmental issues related to the ingredients used in cosmetic formulations, drives the interest to use greener and more sustainable raw materials (Rodrigues et al., 2015; Wang et al., 2015).

Products, either in the form of creams or lotions, and including biologically active compounds with medical drug-like benefits (Epstein, 2009; Taofiq et al., 2016a), are termed "cosmeceuticals". This concept that gained importance in the last couple of years has rapidly expanded driven by the enormous availability of novel ingredients of natural origin (Draelos, 2008). Bioactive extracts from medicinal plants, microbial metabolites, mushrooms and algae metabolites have been reported to present remarkable bioactive properties (e.g. anti-collagenase, antioxidant, anti-elastase, anti-hyaluronidase, antiinflammatory and anti-tyrosinase activities) for the development of skin care formulations (De Wet et al., 2013; Ding et al., 2016; Tamrakar et al., 2017; Taofiq et al., 2018, 2017a).

Mushrooms are globally consumed not only because of their nutritional properties but also for their medicinal potential and richness in

\footnotetext{
* Corresponding author.

E-mail address: iferreira@ipb.pt (I.C.F.R. Ferreira).
} 
several bioactive compounds (Heleno et al., 2015; Taofiq et al., 2017b, 2016a). Owing to this context, as well as to their increasing use as nutraceuticals, mushrooms' market has grown tremendously over the years (Ferreira et al., 2015; Rathore et al., 2017; Taofiq et al., 2017b). Having in mind the high amount of bio-wastes generated by the related mushroom processing industry, the need to find profitable solutions for their reuse is of economic, environmental and scientific interest (Heleno et al., 2016).

Mushroom cosmeceutical ingredients are gradually entering the cosmetic market, and this is evident by the number of commercial cosmeceutical formulations containing mushroom extracts and/or their bioactive ingredients claiming beneficial effects against fine lines, wrinkles, ageing, skin texture, photoprotection and pigmentation (Taofiq et al., 2016a; Wu et al., 2016). The evaluation of the dermatological potential of new cosmeceuticals comprises the assessment of: (i) the relevant bioactive properties for the skin; (ii) the penetration thought stratum corneum and the needed deliver concentration over time; and (iii) the efficacy and safeness without cytotoxicity, irritation or sensitization (Levin et al., 2010).

Following studies where the cosmeceutical potential of ethanolic extracts of Pleurotus ostreatus (Jacq. ex Fr.) P. Kumm) (Taofiq et al., 2018, 2016b) and Ganoderma lucidum (Curtis) P.Karst (Taofiq et al., 2017b). was demonstrated, these extracts were selected for the present work. Both extracts, obtained by Soxhlet extraction, and their corresponding final cosmetic formulations, prepared from a selected based cream, were tested regarding cell viability and cytotoxic effects using MTT and LDH assays in keratinocytes (HaCaT) and fibroblasts (HFF-1). Additionally, the extracts and the final formulations were submitted to skin permeation assays using the Franz diffusion cell with pig ear skin as the permeation membrane.

\section{Material and methods}

\subsection{Mushroom samples}

Fresh samples of Pleurotus ostreatus (Jacq. ex Fr.) P. Kumm) were purchased from a local supermarket in Bragança at the Northeast of Portugal $\left(41.8061^{\circ} \mathrm{N}, 6.7567^{\circ} \mathrm{W}\right)$. For each mushroom species, the fruiting bodies were dried at $30^{\circ} \mathrm{C}$ in an oven and reduced to a fine powder (20 mesh) for further extraction and analysis. The fruiting bodies of Gandoderma lucidum (Curtis) P. Karst. were provided by Bioreishi - Agricultura Biológica, Lda, Portugal (Reishi producers; Batalha, Portugal) as dry material. The specimens were reduced to powder (20 mesh). For all the experiments three samples were analysed and all the assays were carried out in triplicate. The results are expressed as mean values \pm standard deviation (SD).

\subsection{Preparation of the mushroom ethanolic extracts}

The powdered samples $(3.0 \mathrm{~g}$ ) were extracted with $100 \mathrm{~mL}$ of ethanol by refluxing in a Soxhlet apparatus. The obtained extract solutions were filtered through a Whatman paper no 4 and then dried under reduced pressure to remove the solvent and recover the solid extract. The extraction yield was expressed as percentage $(\%, w / w)$ calculated by dividing the weight of the recovered extract (extract, E) by the weight of the used dry sample.

\subsection{Preparation of the base creams added with the extracts}

A Versatile ${ }^{\mathrm{TM}}$ cream base formulation, free from fragrances, colorants, parabens, mineral oils, sodium lauryl sulphate (SLS), propylene glycol, and ethoxylates was purchased from Fagron Iberica S.A.U. (Barcelona, Spain). According to the provided technical data, this formulation is certified to be safe by the US Food and Drug Administration (FDA), Regulation (EC) No 1907/2006-REACH and the National Health Surveillance Agency (ANVISA) of Brazil. The cosmeceutical creams were formulated according to the procedure reported by Taofiq et al. (2016b). Shortly, the base creams were supplemented, separately, with each extract at a percentage of $2.5 \%(\mathrm{w} / \mathrm{w})$ corresponding to $25 \mathrm{mg}$ per gram base cream. The formulations were mixed properly to ensure sample homogenisation and then stored in tightly closed vials at $4^{\circ} \mathrm{C}$.

\section{4. $\mathrm{pH}$ and colour determination}

The colour and $\mathrm{pH}$ measurements were performed according to the work of Taofiq et al. (2018). Briefly, the colour was measured using a colorimeter (model CR-400, Konica Minolta Sensing Inc., Tokyo, Japan) by sampling in three different points, and by considering the average as the true colour value. Colour space values were registered using the data software "Spectra Magic Nx" (version CM-S100W 2.03.0006). The $\mathrm{pH}$ measurement was measured, in triplicate, directly in the cream with a HI 99161 pH-meter (Hanna Instruments, Woonsocket, Rhode Island, USA).

\subsection{In vitro evaluation of cell viability and cytotoxic effects in skin cell lines}

Two different assays were used to assess cell integrity and cytotoxicity of the extracts and final cosmetic formulations: (1) monitoring the uptake of the vital mitochondrial dye, 3-(4,5-dimethylthiazol-2-yl)5-(3-carboxymethoxyphenyl)-2-(4-sulfophenyl)-2H-tetrazolium(MTT) by cell mitochondria and (2) determining the leakage of the cytosolic enzyme, lactate dehydrogenase (LDH) into the cell medium (LDH assay). For the cell treatment, samples were dissolved in DMEM and subsequent dilutions were prepared from $1 \mu \mathrm{g} / \mathrm{mL}$ to $10 \mathrm{mg} / \mathrm{mL}$. In both tests, triplicate wells were incubated with fresh medium in the absence or presence of samples.

Cell lines and culture conditions. Human immortalized non-tumorigenic keratinocyte cell line HaCaT (Ethnicity, Caucasian; age, 62 years; gender, male and tissue, skin) was supplied by CLS Cell Lines Service, Germany. Human foreskin fibroblasts (HFF-1) were purchased from ATCC (ATCC Number: SCRC-1041; ATCC, Manassas, VA). Each cell lines were grown separately in tissue culture flasks (OrangeScientific, Belgium). Cell lines were grown in DMEM medium (Carlsbad, CA) fortified with L-glutamine, 10\% inactivated fetal calf serum (FBS), antibiotic-antimitotic mixture (final concentration of $100 \mathrm{U} / \mathrm{mL}$ Penicillin and $100 \mathrm{U} / \mathrm{mL}$ Streptomycin) maintained in $5 \% \mathrm{CO}_{2}$ incubator (Cell Culture $\mathrm{CO}_{2}$ Incubator, ESCO GB Ltd., UK). At 90-95\% confluence, cells were trypsinized and plated in microtiter dishes. The viable cells were counted using trypan blue dye (Gibco) in hemocytometer.

MTT assay. Cell viability was assessed using the 3-(4,5-dimethylthiazol-2-yl)-5-(3-carboxymethoxyphenyl)-2-(4-sulfophenyl)$2 \mathrm{H}$-tetrazolium (MTT purchased from Promega, Madison, WI) conversion assay. Cells were cultured in 96-well micro titter plate at a density of $25 \times 10^{3}$ cells per $\mathrm{mL}$ culture medium for $24 \mathrm{~h}$. Then, cells were incubated with $1 \mu \mathrm{g} / \mathrm{mL}-10 \mathrm{mg} / \mathrm{mL}$ of both extracts and its corresponding formulation, for $24 \mathrm{~h}$ at $37^{\circ} \mathrm{C}$. After the removal of samples from the wells, cells were washed in phosphate-buffered saline, followed by addition of fresh medium. The micro titter plates were then incubated in a humidified atmosphere of $5 \% \mathrm{CO}_{2}$ at $37^{\circ} \mathrm{C}$ for $24 \mathrm{~h}$. To evaluate the number of viable cells, $100 \mu \mathrm{L}$ of MTT solution was added into each well and incubated for $4 \mathrm{~h}$ at $37^{\circ} \mathrm{C}$ in the dark. Afterwards, the medium was removed, the intracellular formazan crystals were solubilized and extracted with $100 \mu \mathrm{L}$ dimethylsulfoxide (DMSO). After $15 \mathrm{~min}$ in continuous stirring at room temperature, the absorbance was measured at $490 \mathrm{~nm}$ with background subtraction at $630 \mathrm{~nm}$ in a Synergy HT Microplate Reader (BioTek Instruments, Inc., Winooski, VT) (Rodrigues et al., 2013).

LDH assay. Briefly, cell lines were seeded in 96-well plates and cultured for $48 \mathrm{~h}$. Extract and their corresponding formulation at different concentrations was prepared in appropriate medium and added to the cells. After incubation $\left(37 \mathrm{C} / 5 \% \mathrm{CO}_{2}\right)$, cells were washed twice 
with PBS (pH 7.4) and the LDH kit (Takara Bio Inc., Shiga, Japan) was used according to the instructions of the manufacturers. To determine maximum LDH release (high control), some cells were solubilized with a final concentration of $1 \%(\mathrm{w} / \mathrm{v})$ Triton X-100 (Boehringer Mannheim). Absorbance was measured at $490 \mathrm{~nm}$ with background subtraction at $690 \mathrm{~nm}$ in a Synergy HT Microplate Reader (BioTek Instruments, Inc., Winooski, VT). Each concentration was tested in triplicate in three independent experiments (Rodrigues et al., 2013).

\subsection{Ex vivo skin permeation studies}

Skin model. Porcine ear skin was freshly obtained from a slaughter house in Porto, Portugal. Preparation of the porcine skin samples consisted of cleaning with water to remove debris and drying them with paper towels. The prepared skin was protected with aluminium foil and frozen at $-20^{\circ} \mathrm{C}$ until required. Before each test, the skin was placed in $0.9 \% \mathrm{NaCl}$ solution at room temperature for rehydration.

Franz diffusion cells. The Franz diffusion cell system was used to test the penetration of compounds present in the ethanolic extract of $P$. ostreatus and $G$. lucidum and their corresponding formulations. A Franz cell assembly ( $9 \mathrm{~mm}$ unjacketed Franz Diffusion Cell) comprising a 5$\mathrm{mL}$ receptor volume and a diffusion area of $0.8 \mathrm{~cm}^{2}$ (PermeGear, Inc. Pennsylvania USA) was used. The skin cells were placed between donor and the receptor phase with the stratum corneum side facing upward into the donor compartment. The donor medium consisted of $300 \mu \mathrm{L}$ $(500 \mu \mathrm{g} / \mathrm{mL})$ in the case of ethanolic extracts and $100 \mathrm{mg}$ of formulation accurately spread on the skin membrane with the help of a spatula. The receptor $(5 \mathrm{~mL})$ was filled with PBS buffer. The stirring rate and temperature of receptor solution were, respectively, kept at $600 \mathrm{rpm}$ and $37^{\circ} \mathrm{C}$. At appropriate intervals $(15 \mathrm{~min}, 30 \mathrm{~min}, 45 \mathrm{~min}, 1 \mathrm{~h}, 2 \mathrm{~h}, 4 \mathrm{~h}, 6 \mathrm{~h}$ and $8 \mathrm{~h}) 600 \mu \mathrm{L}$ aliquots of the receptor medium were withdrawn with a syringe and immediately replaced with equal volumes of fresh receptor phase (Casiraghi et al., 2017). The cumulative quantity of compounds was determined by HPLC-DAD-ESI/MS.

Chromatographic analysis. Identification and quantification of individual triterpenes and phenolic acids were carried out using a Dionex Ultimate 3000 UPLC system (Thermo Scientific, San Jose, CA, USA) previously described by Taofiq et al. (2017). Data was collected simultaneously with DAD $(280 \mathrm{~nm})$ and in negative mode detection on a Linear Ion Trap LTQXL mass spectrometer (Thermo Scientific, San Jose, CA, USA). Xcalibur ${ }^{\circ}$ data system (Thermo Scientific, San Jose, CA, USA) was used for data acquisition. For identification, retention times, UVVIS and mass spectra were compared with the ones of available standards. When not available, data from literature was used to tentatively identify the remaining compounds. Quantification was based on calibration curves of available phenolic and triterpenoid standards constructed based on the UV signal. Compounds with unavailable commercial standards were quantified using the calibration curve of the most similar available standard.

\subsection{Statistical analysis}

All assays were carried out in triplicate and results were expressed as mean values and standard deviation (SD). The results were analysed using one-way analysis of variance (ANOVA) followed by Tukey's HSD test with $\alpha=0.05$. A Student's $t$-test was used to determine the significant difference among two different samples, with $\alpha=0.05$. Statistical analysis of the results was performed using SPSS v. 23.0 program (IBM Corp., Armonk, New York, USA).

\section{Results and discussion}

\subsection{Description of the developed cosmeceutical formulations}

Ethanolic extracts obtained from G. lucidum and P. ostreatus (E1 and $\mathrm{E} 2$, respectively) were incorporated into semi-solid base creams and the generated formulations designated as F1 and F2 for G. lucidum and P. ostreatus, respectively. The incorporated extracts may have a positive effect on the skin when applied topically due to their content in different bioactive molecules (e.g triterpenoids, phenolic acids and related compounds), as well as the bioactive properties previously reported (Taofiq et al., 2018, 2017b; 2016b). The colour attributes of the produced formulations in the $L^{*} a^{*} b^{*}$ system were $70.3 \pm 0.7$, $12.1 \pm 0.5,32.9 \pm 0.9$ and $88.3 \pm 0.5,0.21 \pm 0.02,19.01 \pm 0.4$ for F1 and F2, respectively. Both formulations present $\mathrm{pH}$ between 3.4 and 4.7 and can be considered adequate for topical application. Natural extracts, or their individual metabolites, offer many advantages as cosmeceutical ingredients and are being increasingly used nowadays. They assume importance not just because of the bioactive potential but also due to the commercial and market appeal, making them positively recognized and accepted by consumers.

\subsection{Safety of the ethanolic extracts and cosmeceutical formulations}

In the present work, the cell viability effect of the ethanolic extracts prepared from $G$. lucidum and $P$. ostreatus was evaluated on HaCaT (keratinocytes) and HFF-1 (fibroblast) cells, following a concentration dependent manner $(1-10000 \mu \mathrm{g} / \mathrm{mL})$. Keratinocytes are a biologically relevant target for skin irritants because they are the first living cells that contact topically with the applied compounds. Also, HaCaT cells present several morphological and functional features typical of normal epidermal keratinocytes, making them a good model for skin toxicity tests (Abruzzo et al., 2017). The chemical profile of the ethanolic extracts from $G$. lucidum and P. ostreatus (data not shown) correspond to a mixture of different bioactive compounds, which potentiate the development of reactions (allergic or irritant) when applied for dermatologic purposes, imposing the need to perform cytotoxicity evaluation and access the minimum concentration reducing the viability of the tested cell lines.

Regarding HaCaT cells after exposure to both extracts (Fig. 1), up to $90 \%$ cell viability was maintained at $100 \mu \mathrm{g} / \mathrm{mL}$, while the highest tested concentration $(10 \mathrm{mg} / \mathrm{mL})$ was found to significantly inhibit cell viability. Concerning HFF-1 cells, the cell viability was maintained up to $60 \%$ at $100 \mu \mathrm{g} / \mathrm{mL}$ for $\mathrm{E} 1$, and up to $90 \%$ when the same concentration was used with E2. Above $100 \mu \mathrm{g} / \mathrm{mL}$, both extracts were found to significantly affect the viability of HFF-1 cells as shown in Fig. 2. This result can be used to compare the potential toxicity of the studied mushroom ethanolic extracts, based on which further experiments can be conducted.

The LDH assay has been utilised as a good marker to ascertain cytotoxicity of bioactive ingredients. The mechanism behind it involves the measurement of lactate dehydrogenase (LDH), an enzyme found in the surroundings of compromised cell membranes. As shown in Fig. 3, E2 did not show any potential to cause LDH leakage after exposure to HaCaT cells. This low toxicity was achieved at $100 \mu \mathrm{g} / \mathrm{mL}$, more than $50 \%$ toxicity was found above $1 \mathrm{mg} / \mathrm{mL}$. In what concerns $\mathrm{E} 1$, a lower level of toxicity was found in the range of $4-100 \mu \mathrm{g} / \mathrm{mL}$, while increased cellular LDH efflux was found above $100 \mu \mathrm{g} / \mathrm{mL}$. Similarly, Fig. 4 showed that both extracts present low toxicity to HFF-1 cells between 1 and $10 \mu \mathrm{g} / \mathrm{mL}$, but increased LDH level was observed between 100 and $10000 \mu \mathrm{g} / \mathrm{mL}$ for both extracts, comparable to Triton X100 (negative control). The results indicate that the fibroblasts cells were more sensitive when compared to the keratinocytes after exposure to different concentrations of the extracts. These results are in agreement with those obtained for hydroalcoholic extract obtained from the leaves of six species of Medicago (Rodrigues et al., 2013). The authors observed that the keratinocytes were more resistant than fibroblasts when exposed to different concentrations of the extract. Based on the achieved results described, the extract concentration that was able to maintain cell viability up to $50 \%$ can be selected for further experiments or applications.

The final cosmeceutical creams formulated with the extracts were 


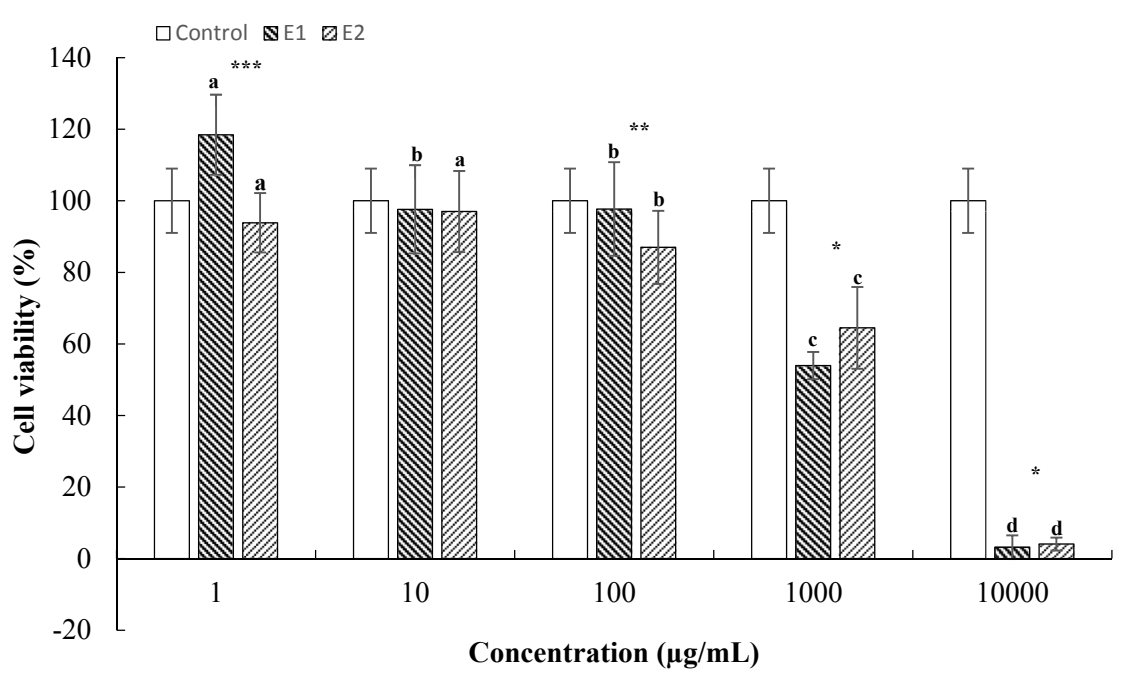

Fig. 1. Cell viability effects of $G$. lucidum (E1) and P. ostreatus (E2) ethanolic extracts on HaCaT cells at different concentrations, as measured by the MTT assay. Values are expressed as means $\pm \mathrm{SD}(\mathrm{n}=3)$. Asterisks denote statistically significant differences compared between the two extracts in the same concentration ( ${ }^{*} \mathrm{p}<0.5$, $* * \mathrm{p}<0.001, * * * \mathrm{p}<0.0005)$. In each extract, different letters mean significant differences between the concentrations ( $\mathrm{p}<0.05)$. also submitted to studies evaluating their cell viability on fibroblasts and keratinocyte cell lines. Data of Fig. 5 indicates that the cell viability of HaCaT cell lines, after exposure to $\mathrm{F} 1$, undergo, up to $60 \%$, maintenance of cell viability at $1 \mathrm{mg} / \mathrm{mL}$. The effect of $\mathrm{F} 2$ on cell viability of HFF-1 (Fig. 6) showed a cell survival rate of $\sim 60 \%$ for all concentrations below $100 \mu \mathrm{g} / \mathrm{mL}$, while $1 \mathrm{mg} / \mathrm{mL}$ and $10 \mathrm{mg} / \mathrm{mL}$ were found to be deleterious to the cells. In fact, it is difficult to deduce the cytotoxic contribution of each component present in the base cream, as well as the contribution of the individual compounds identified in the extracts. To the author's best knowledge, this is the first study evaluating the safety of a final cosmetic formulation supplemented with phenolic and triterpenoid rich extracts obtained from mushrooms.

Most products introduced into the market by cosmeceutical manufacturers undergo self-policing since no dedicated regulation for safety is available. Some of these ingredients can trigger several allergies; hence, setting up approaches and methods to identify allergens and evaluate the potential toxicity of some of these products is of huge importance (Draelos, 2009). The presence of a diversity of chemical compounds in bioactive extracts may triggers some unwanted skin irritations, contact dermatitis, photosensitivity, hair and nail damage, hyperpigmentation, hypopigmentation and systemic effects (Gao et al., 2008). Since these ingredients are going to be in contact with the skin, it is vital to evaluate their safety and potential toxicity against skin cells. Over the years, in vitro models were developed to mimic skin cells and assess the safety and potential toxicity of bioactive extracts intended for dermatological use (Rodrigues et al., 2013).

\subsection{Ex vivo skin permeation}

To identify which of the naturally occurring compounds of the prepared ethanolic extracts from $G$. lucidum and $P$. ostreatus were able to penetrate through the skin, and to evaluate their permeability, ex vivo experiments were conducted using a pig skin model. From the results described in Table 1, in what concerns skin penetration profile of E1, significant amounts of compounds were found to penetrate the skin, but these compounds were not detected in the receptor compartment. The results showed that a significant percentage of the compounds earlier detected in the extract were retained in the skin layers. It will be of utmost significance if these compounds retained in the skin layers can elicit a local cosmeceutical effect. Different factors such as higher molecular weight, lipophilicity and aqueous solubility have been reported to be the most important determining factors that explains the tendency of compounds to permeate or to be retained on the skin surface (Žilius et al., 2013).

Protocatechuic and syringic acids were the unique compounds that penetrated from the E1 extract suspension through the skin in an amount that could be quantified after $8 \mathrm{~h}$, as shown in Table 2. Both compounds were also detected in the receptor compartment of formulation F1 test. Phenolic acids and related compounds identified in the E2 extract are cinnamic, $p$-hydroxybenzoic and $p$-coumaric acids, and none of these compounds were detected in the receptor fluid, up to $8 \mathrm{~h}$ of assayed time. This finding was an indication of the low skin permeation of extracts prepared from $P$. ostreatus. Similarly, the

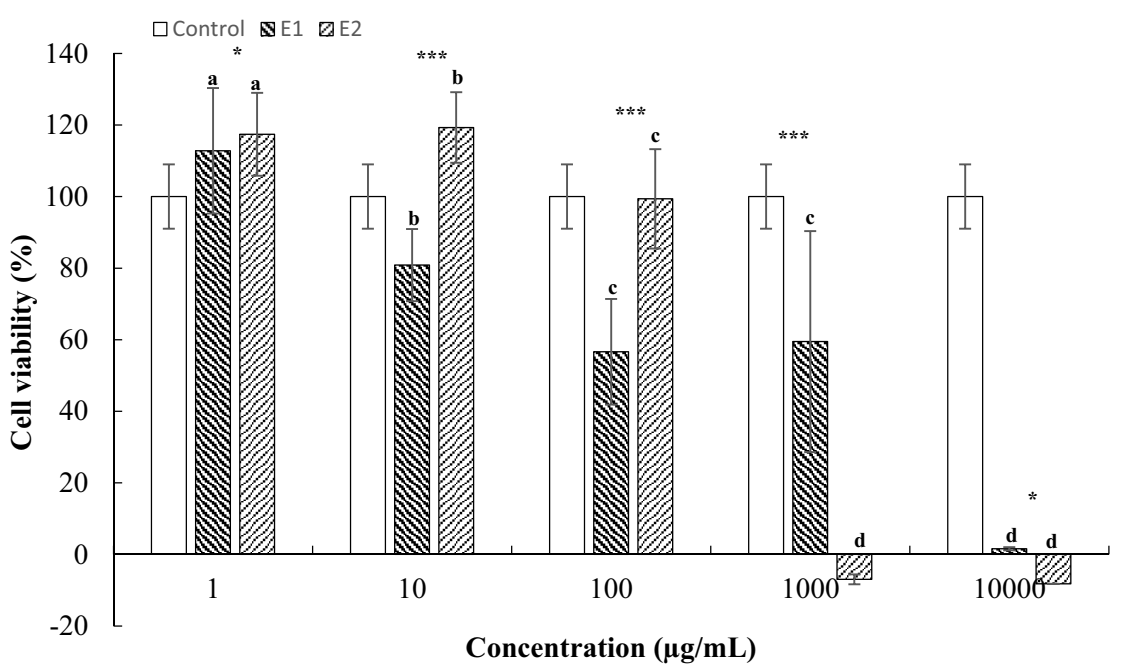

Fig. 2. Cell viability effects of G. lucidum (E1) and P. ostreatus (E2) ethanolic extracts on HFF-1 cells at different concentrations, as measured by the MTT assay. Values are expressed as means $\pm \mathrm{SD}(\mathrm{n}=3)$. Asterisks denote statistically significant differences compared between the two extracts in the same concentration $(* \mathrm{p}<0.5$, $* * \mathrm{p}<0.001, * * * \mathrm{p}<0.0005)$. In each extract, different letters mean significant differences between the concentrations $(\mathrm{p}<0.05)$. 


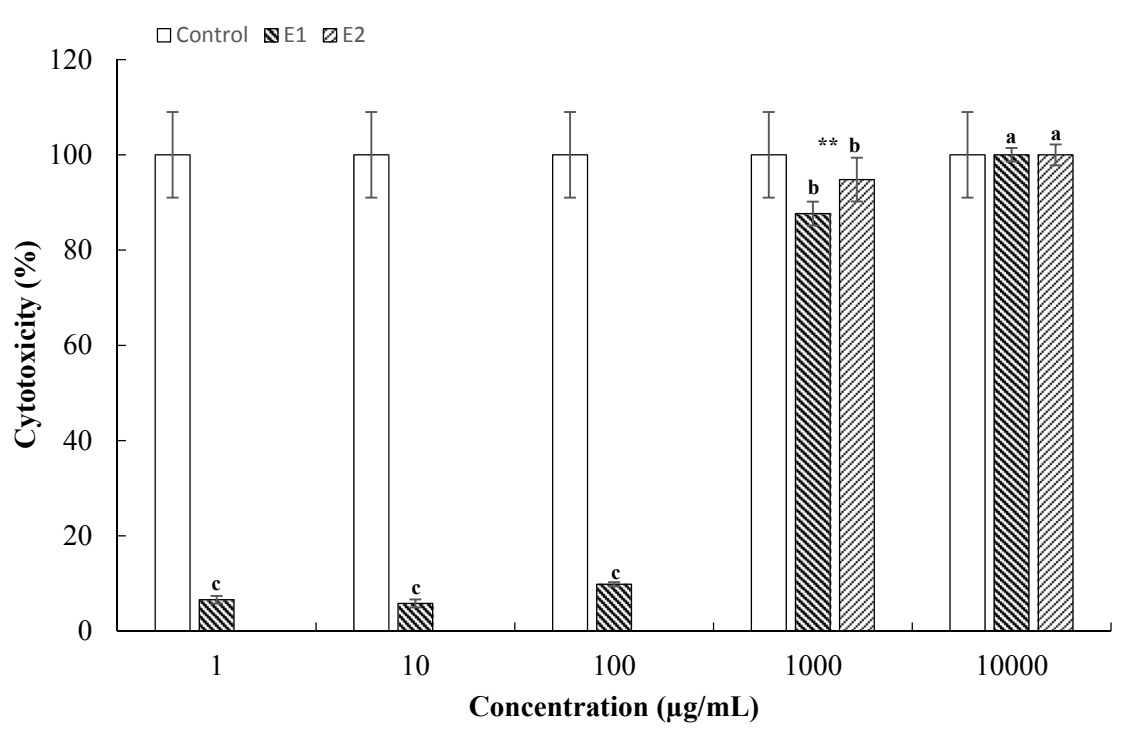

Fig. 3. Cytotoxicity (\%) of LDH in HaCaT cells after exposure to extracts E1 and E2. Values are expressed as means \pm SD $(n=3)$. Asterisks denote statistically significant differences compared between the two extracts in the same concentration $\left({ }^{*} \mathrm{p}<0.5,{ }^{* *} \mathrm{p}<0.001\right.$, $* * * \mathrm{p}<0.0005)$. In each extract, different letters mean significant differences between the concentrations $(\mathrm{p}<0.05)$. penetration and permeation of compounds in formulation F2 was very low and no compounds were detected in the receptor compartment. The results showed that the penetration ability of the phenolic acids identified in the receptor compartment of the assays with sample E1 and F1 might be due to the enhanced contribution of the high size triterpenes of E1 and corresponding formulation. Studies have identified triterpenes, terpenes and sesquiterpenes as promising non-toxic, highly advanced, non-irritating transdermal penetration enhancers, which were classified as generally regarded as safe (GRAS) by the Food and Drug Administration (Aqil et al., 2007). The results of E1 and F1 samples (Tables 2 and 3) showed that the amounts of compounds penetrating in the F1 case were higher than the ones of E1 extract suspension. These results are in agreement with the ones reported by Tachaprutinun et al. (2014) in which the authors confirmed that the properties of the base cream (vehicle) have a significant impact on the penetration of the active ingredients.

Bioactive ingredients present in cosmeceutical formulations must be released from the carrier (base cream) and be able to penetrate the stratum corneum of the skin in order to deliver a cosmeceutical effect (Rodrigues et al., 2016). Because of the ban on the use of in vivo assays for testing cosmetics ingredients, in the cosmetic directive 76/768/EEC there is a demand for novel in vitro methods to determine the bioavailability of topically applied chemicals (Gerstel et al., 2016). Skin permeation studies have been conducted in the past using human skin as membrane, but these experiments are expensive and sometimes limited due to ethical issues. Penetration studies with human and pig skin have been conducted and the results have shown that both skin cells demonstrate positive correlation and bioavailability distribution in the different skin layers with comparable and reproducible results (Barbero and Frasch, 2009; Diembeck et al., 1999). Histologically many similarities are observed such as the tissue turnover time, the SC thickness, the hair-follicle density and the characteristics of their keratinous proteins. However, dissimilarities exist in the level of vascularization, fat component of the SC organized in hexagonal lattice in pigs and orthorhombic lattice in human (Praça et al., 2018). The goal is the permeation of active ingredients in stratum corneum, which is popularly referred to as the rate limiting barrier before successfully permeating through the epidermis (Haq et al., 2018).

Various types of bioactivities have been reported for triterpenes and phenolic acids, such as antimicrobial, anti-inflammatory and antioxidant properties (Alves et al., 2013; Heleno et al., 2015; Taofiq et al., 2015). In vitro studies have shown that syringic acid present anti-inflammatory activity due to the ability to suppress iNOS and COX-2 activity (Lee et al., 2013; Stanikunaite et al., 2009). On the other hand, protocatechuic acid presents hyperpigmentation potential due to its ability to inhibit tyrosinase enzyme (Sahin, 2018). Hence, when applied

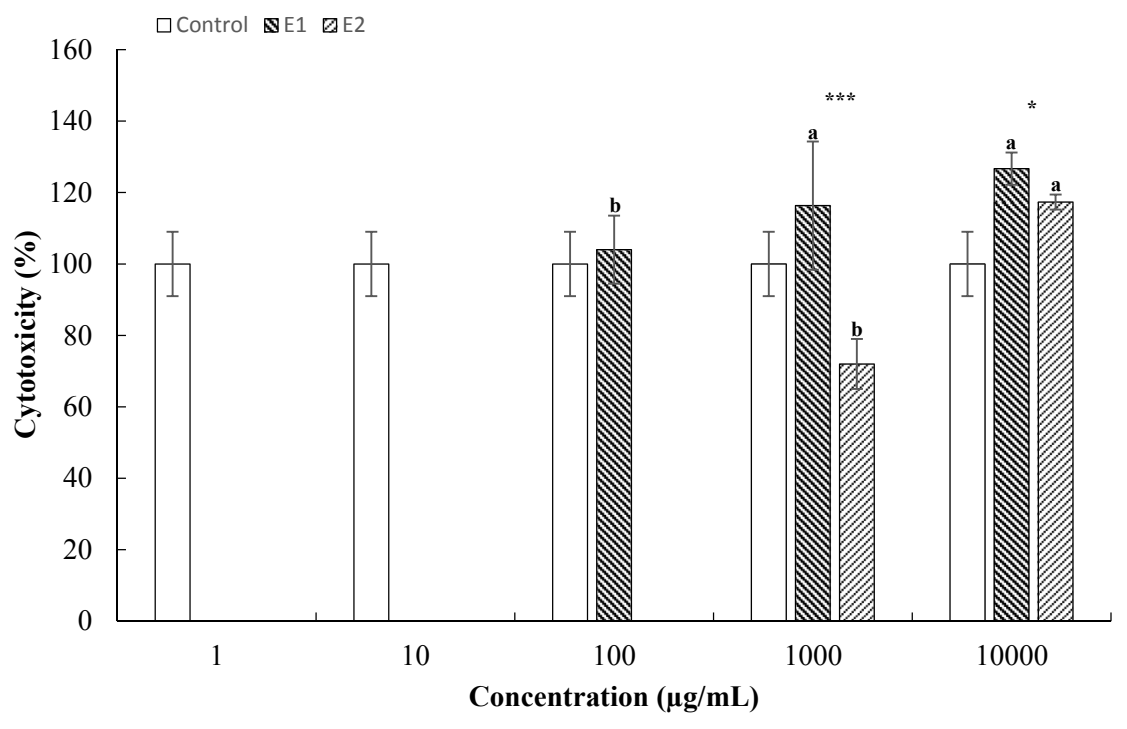

Fig. 4. Cytotoxicity (\%) of LDH in HFF-1 cells after exposure to extracts E1 and E2. Values are expressed as means \pm SD $(n=3)$. Asterisks denote statistically significant differences compared between the two extracts in the same concentration (*p $\left.<0.5,{ }^{* *} \mathrm{p}<0.001,{ }^{* * *} \mathrm{p}<0.0005\right)$. In each extract, different letters mean significant differences between the concentrations $(\mathrm{p}<0.05)$. 

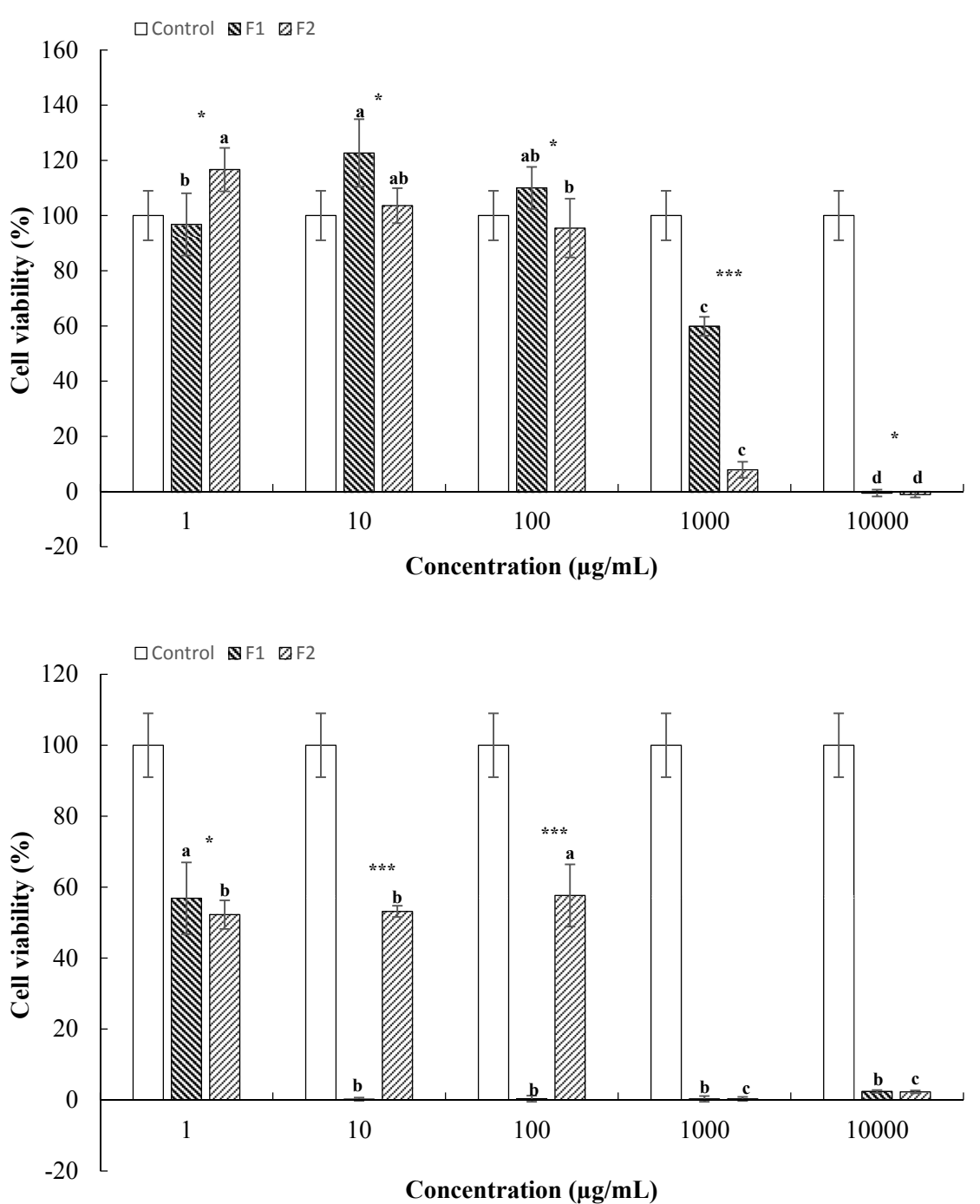

Fig. 5. Cell viability effects of formulations (F1 and F2) on $\mathrm{HaCaT}$ cells at different concentrations, as measured by the MTT assay. Values are expressed as means \pm SD $(n=3)$. Asterisks denote statistically significant differences compared between the two extracts in the same concentration ( $\left.{ }^{*} \mathrm{p}<0.5,{ }^{* *} \mathrm{p}<0.001,{ }^{* * *} \mathrm{p}<0.0005\right)$. In each extract, different letters mean significant differences between the concentrations ( $\mathrm{p}<0.05$ ).
Fig. 6. Cell viability effects of formulations (F1 and F2) on HFF-1 cells at different concentrations, as measured by the MTT assay. Values are expressed as means $\pm \operatorname{SD}(\mathrm{n}=3)$. Asterisks denote statistically significant differences compared between the two extracts in the same concentration ( $\left.{ }^{*} \mathrm{p}<0.5,{ }^{* * \mathrm{p}}<0.001,{ }^{* * *} \mathrm{p}<0.0005\right)$. In each extract, different letters mean significant differences between the concentrations ( $\mathrm{p}<0.05)$. to the skin, F1 formulation will be able to deliver these potential antioxidant and anti-inflammatory compounds for a long period of time as shown in Table 3. Abla and Banga (2013) have reported the permeation of catechin and resveratrol using porcine ear skin, which was favoured due to the use of propylene glycol that acts as a penetration enhancer. A more significant amount of catechin was retained in the stratum corneum whereas only $10 \%$ was able to be quantified in the underlying skin. Other authors suggested that the release of phenolic compounds from semisolid vehicles is influenced, not only by the physiochemical properties of the bioactive ingredient, but also by the properties of the used vehicle, as well as by the concentration of the bioactive in the formulation. The above phenomena were reported by Žilius et al. (2013) after $8 \mathrm{~h}$ of ex vivo skin permeation experiments, where over $90 \%$ of the phenolic compounds were released from a hydrophilic gel, and only up to $5 \%$ and $22 \%$ of phenolic compounds were released from ointment and water-in-oil (w/o) cream, respectively. These results demonstrated that the E1 ethanolic extract can be utilised as an ingredient for cosmeceutical application due to the beneficial biological properties of its individual compounds (protocatechuic and syringic acids). After topical application, they penetrate the skin, offering advantages as an antioxidative support to the skin, suppressing oxidative stress and protecting the skin against photo-aging.

\section{Conclusion}

Presently, there is an awareness of cosmetic users concerning the used ingredients. Recent market trends involve the use of bioactive ingredients from natural sources to obtain products with skin benefits and with less toxic effects. In this study, extracts rich in phenolic compounds and triterpenoids were obtained from $P$. ostreatus and $G$. lucidum using a Soxhlet extraction system. An in vitro analysis of their safeness as dermatological ingredients was carried out. The displayed results are good indicators of extract's suitability for skin care formulations as the absence of toxicity in keratinocytes and fibroblasts is indicative of their potential safety. The corresponding formulation developed using the $G$. lucidum ethanolic extract was able to retain some of the bioactive compounds, and dermal penetration was detected mainly for phenolic acids. Comparatively, the skin permeation studies with the formulation based on $P$. ostreatus extract showed very low permeation of their phenolic acids. The results herein justify the contribution of triterpenoids as penetration enhancing ingredients. The mushroom industry continues to generate large amounts of wastes during their processing, with these bio-residues available to be used as inexpensive sources of raw materials for valuable cosmetic ingredients. Further studies should focus on several novel in vitro models to evaluate the safety and toxicity of cosmeceutical ingredients. Also, commercially available reconstructed human epidermis models such as EpiSkin, SkinEthic and EpiDerm can be utilised to evaluate the absorption and permeability of these ingredients, and to test phototoxicity, corrosivity and irritancy. 


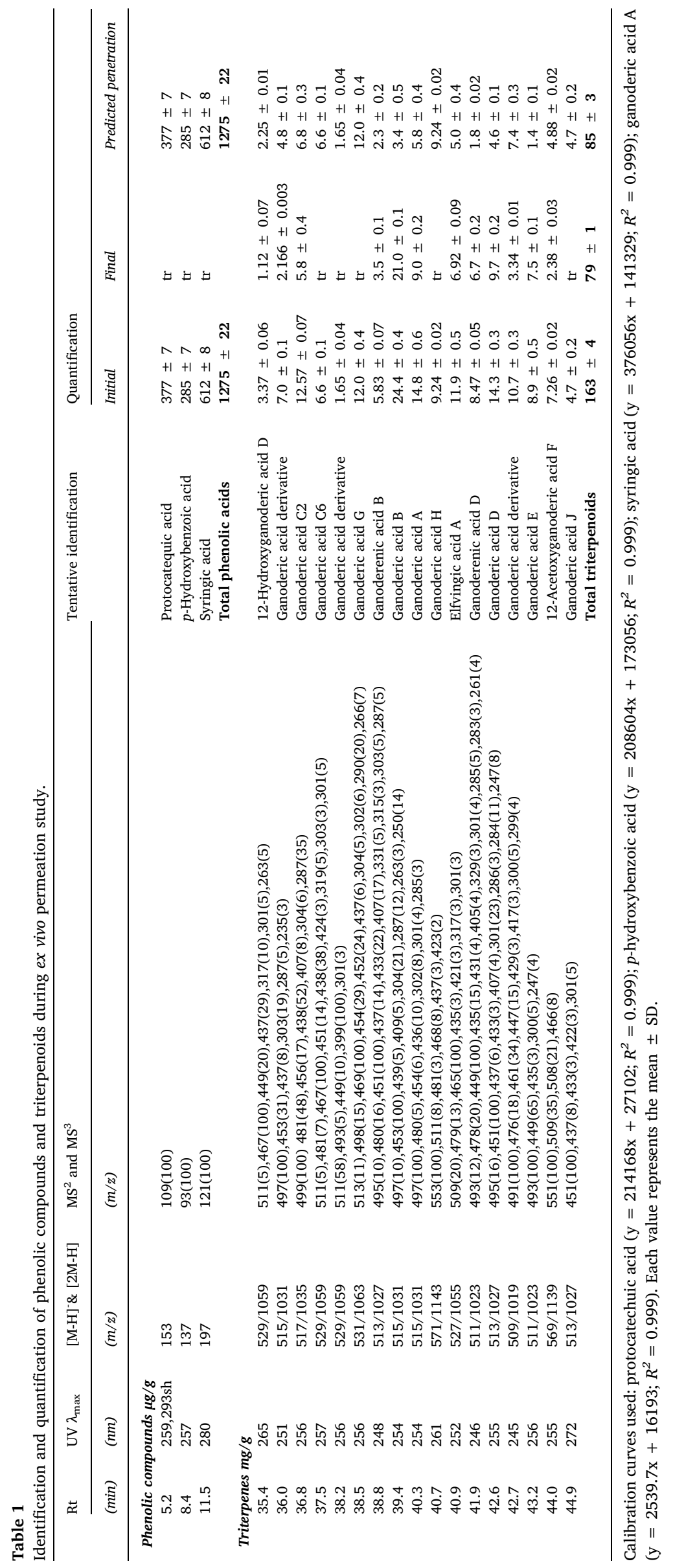


Table 2

Skin permeation profile of the extract E1.

\begin{tabular}{lll}
\hline Time & Compounds & Amount detected in receptor compartment $(\mu \mathrm{g} / \mathrm{g})$ \\
\hline $15 \mathrm{~min}$ & - & - \\
$30 \mathrm{~min}$ & - & - \\
$45 \mathrm{~min}$ & - & - \\
$1 \mathrm{~h}$ & Protocatechuic acid & $51.5 \pm 0.4$ \\
$2 \mathrm{~h}$ & Protocatechuic acid & $35.3 \pm 0.2$ \\
$4 \mathrm{~h}$ & Protocatechuic acid & $11.5 \pm 0.1$ \\
& Syringic acid & $37.2 \pm 0.4$ \\
$6 \mathrm{~h}$ & Protocatechuic acid & $12.1 \pm 0.1$ \\
$8 \mathrm{~h}$ & - & - \\
\hline
\end{tabular}

Each value represents the mean \pm SD.

Table 3

Skin permeation profile of the formulation F1.

\begin{tabular}{lll}
\hline Time & Compounds & Amount detected in receptor compartment $(\mu \mathrm{g} / \mathrm{g})$ \\
\hline $15 \mathrm{~min}$ & - & - \\
$30 \mathrm{~min}$ & Protocatechuic acid & $19.7 \pm 0.1$ \\
& Syringic acid & $73 \pm 1$ \\
$45 \mathrm{~min}$ & Syringic acid & $66 \pm 1$ \\
$1 \mathrm{~h}$ & Syringic acid & $32.6 \pm 0.2$ \\
$2 \mathrm{~h}$ & Protocatechuic acid & $52 \pm 1$ \\
& Syringic acid & $28 \pm 1$ \\
$4 \mathrm{~h}$ & Syringic acid & $46 \pm 1$ \\
$6 \mathrm{~h}$ & Syringic acid & $50 \pm 1$ \\
$8 \mathrm{~h}$ & - & -
\end{tabular}

Each value represents the mean \pm SD.

\section{Acknowledgements}

The authors are grateful to the Foundation for Science and Technology and FEDER under Programme PT2020 for financial support to CIMO (UID/AGR/00690/2019) and Associate Laboratory LSRE-LCM (UID/EQU/50020/2019) funded by national funds through FCT/ MCTES (PIDDAC). This work is funded by the European Agricultural Fund for Rural Development (EAFRD), through the Rural Development Program (PDR2020), within the scope of Project MicoCoating (PDR2020-101-031472). Francisca Rodrigues is thankful for her postdoc research grant from the project Operação NORTE-01-0145FEDER- 000011. This work received financial support from the European Union (FEDER funds through COMPETE), under the Partnership Agreement PT 2020, and National Funds (FCT, Foundation for Science and Technology) through project LAQV/UID/QUI/50006/ 2013 and NORTE-07-0124-FEDER-000069 - Food Science.

\section{Appendix A. Supplementary data}

Supplementary data to this article can be found online at https:// doi.org/10.1016/j.fct.2019.03.045.

\section{References}

Abla, M.J., Banga, A.K., 2013. Quantification of skin penetration of antioxidants of varying lipophilicity. Int. J. Cosmet. Sci. 35, 19-26. https://doi.org/10.1111/j.14682494.2012.00728.x.

Abruzzo, A., Armenise, N., Bigucci, F., Cerchiara, T., Gösser, M.B., Samorì, C., Galletti, P., Tagliavini, E., Brown, D.M., Johnston, H.J., Fernandes, T.F., Luppi, B., 2017. Surfactants from itaconic acidToxicity to HaCaT keratinocytes in vitro, micellar solubilization, and skin permeation enhancement of hydrocortisone. Int. J. Pharm. 524, 9-15. https://doi.org/10.1016/j.ijpharm.2017.03.056.

Alves, M.J., Ferreira, I.C.F.R., Froufe, H.J.C., Abreu, R.M.V., Martins, A., Pintado, M., 2013. Antimicrobial activity of phenolic compounds identified in wild mushrooms, SAR analysis and docking studies. J. Appl. Microbiol. 115, 346-357. https://doi.org/ 10.1111/jam.12196.

Aqil, M., Ahad, A., Sultana, Y., Ali, A., 2007. Status of terpenes as skin penetration enhancers. Drug Discov. Today 12, 1061-1067. https://doi.org/10.1016/j.drudis.2007. 09.001.

Barbero, A.M., Frasch, H.F., 2009. Pig and Guinea pig skin as surrogates for human in vitro penetration studies: a quantitative review. Toxicol. Vitro 23, 1-13. https://doi. org/10.1016/j.tiv.2008.10.008.

Casiraghi, A., Ranzini, F., Musazzi, U.M., Franzè, S., Meloni, M., Minghetti, P., 2017. In vitro method to evaluate the barrier properties of medical devices for cutaneous use. Regul. Toxicol. Pharmacol. 90, 42-50. https://doi.org/10.1016/j.yrtph.2017.08.007.

De Wet, H., Nciki, S., van Vuuren, S.F., 2013. Medicinal plants used for the treatment of various skin disorders by a rural community in northern Maputaland, South Africa. J. Ethnobiol. Ethnomed. 9, 1. https://doi.org/10.1186/1746-4269-9-51.

Diembeck, W., Beck, H., Benech-Kieffer, F., Courtellemont, P., Dupuis, J., Lovell, W., Paye, M., Spengler, J., Steiling, W., 1999. Test guidelines for in vitro assessment of dermal absorption and percutaneous penetration of cosmetic ingredients. Food Chem. Toxicol. 37, 191-205. https://doi.org/10.1016/S0278-6915(98)00114-8.

Ding, Q., Yang, D., Zhang, W., Lu, Y., Zhang, M., Wang, L., Li, X., Zhou, L., Wu, Q., Pan, W., Chen, Y., 2016. Antioxidant and anti-aging activities of the polysaccharide TLH-3 from Tricholoma lobayense. Int. J. Biol. Macromol. 85, 133-140. https://doi.org/10. 1016/j.ijbiomac. 2015.12.058.

Draelos, Z.D., 2009. Cosmeceuticals: undefined, unclassified, and unregulated. Clin. Dermatol. 27, 431-434. https://doi.org/10.1016/j.clindermatol.2009.05.005.

Draelos, Z.D., 2008. The cosmeceutical realm. Clin. Dermatol. 26, 627-632. https://doi. org/10.1016/j.clindermatol.2007.09.005.

Epstein, H., 2009. Cosmeceuticals and polyphenols. Clin. Dermatol. 27, 475-478. https:// doi.org/10.1016/j.clindermatol.2009.05.011.

Ferreira, I.C.F.R., Heleno, S.A., Reis, F.S., Stojkovic, D., Queiroz, M.J.R.P., Vasconcelos, M.H., Sokovic, M., 2015. Chemical features of Ganoderma polysaccharides with antioxidant, antitumor and antimicrobial activities. Phytochemistry 114, 38-55. https://doi.org/10.1016/j.phytochem.2014.10.011.

Gao, X.H., Zhang, L., Wei, H., Chen, H.D., 2008. Efficacy and safety of innovative cosmeceuticals. Clin. Dermatol. 26, 367-374. https://doi.org/10.1016/j.clindermatol. 2008.01.013.

Gerstel, D., Jacques-Jamin, C., Schepky, A., Cubberley, R., Eilstein, J., Grégoire, S., Hewitt, N., Klaric, M., Rothe, H., Duplan, H., 2016. Comparison of protocols for measuring cosmetic ingredient distribution in human and pig skin. Toxicol. Vitro 34, 153-160. https://doi.org/10.1016/j.tiv.2016.03.012.

Haq, A., Goodyear, B., Ameen, D., Joshi, V., Michniak-Kohn, B., 2018. Strat-M ${ }^{\circledR}$ synthetic membrane: permeability comparison to human cadaver skin. Int. J. Pharm. 547, 432-437. https://doi.org/10.1016/j.ijpharm.2018.06.012.

Heleno, S.A., Martins, A., Queiroz, M.J.R.P., Ferreira, I.C.F.R., 2015. Bioactivity of phenolic acids: metabolites versus parent compounds: a review. Food Chem. 173 , 501-513. https://doi.org/10.1016/j.foodchem.2014.10.057.

Heleno, S.A., Prieto, M.A., Barros, L., Rodrigues, A., Barreiro, M.F., Ferreira, I.C.F.R., 2016. Optimization of microwave-assisted extraction of ergosterol from Agaricus bisporus L. by-products using response surface methodology. Food Bioprod. Process. 100, 25-35. https://doi.org/10.1016/j.fbp.2016.06.006.

Kamble, P., Sadarani, B., Majumdar, A., Bhullar, S., 2017. Nanofiber based drug delivery systems for skin: a promising therapeutic approach. J. Drug Deliv. Sci. Technol. 41, 124-133. https://doi.org/10.1016/j.jddst.2017.07.003.

Kular, J.K., Basu, S., Sharma, R.I., 2014. The extracellular matrix: structure, composition, age-related differences, tools for analysis and applications for tissue engineering. J. Tissue Eng. 5, 1-17. https://doi.org/10.1177/2041731414557112.

Lee, M.H., Kang, H., Lee, K., Yang, G., Ham, I., Bu, Y., Kim, H., Choi, H.Y., 2013. The aerial part of Taraxacum coreanum extract has an anti-inflammatory effect on peritoneal macrophages in vitro and increases survival in a mouse model of septic shock. J. Ethnopharmacol. 146, 1-8. https://doi.org/10.1016/j.jep.2012.12.009.

Levin, J., del Rosso, J.Q., Momin, S.B., 2010. How much do we really know about our favorite cosmeceutical ingredients? J. Clin. Aesthet. Dermatol. 3, 22-41.

Praça, F.S.G., Medina, W.S.G., Eloy, J.O., Petrilli, R., Campos, P.M., Ascenso, A., Bentley, M.V.L.B., 2018. Evaluation of critical parameters for in vitro skin permeation and penetration studies using animal skin models. Eur. J. Pharm. Sci. 111, 121-132. https://doi.org/10.1016/j.ejps.2017.09.034.

Rathore, H., Prasad, S., Sharma, S., 2017. Mushroom nutraceuticals for improved nutrition and better human health: a review. PharmaNutrition 5, 35-46. https://doi.org/ 10.1016/j.phanu.2017.02.001.

Rodrigues, F., Alves, A.C., Nunes, C., Sarmento, B., Amaral, M.H., Reis, S., Oliveira, M.B.P.P., 2016. Permeation of topically applied caffeine from a food by-product in cosmetic formulations: is nanoscale in vitro approach an option? Int. J. Pharm. 513, 496-503. https://doi.org/10.1016/j.ijpharm.2016.09.059.

Rodrigues, F., Palmeira-de-Oliveira, A., das Neves, J., Sarmento, B., Amaral, M.H., Oliveira, M.B., 2013. Medicago spp. extracts as promising ingredients for skin care products. Ind. Crops Prod. 49, 634-644. https://doi.org/10.1016/j.indcrop.2013.06. 015 .

Rodrigues, F., Pereira, C., Pimentel, F.B., Alves, R.C., Ferreira, M., Sarmento, B., Amaral, M.H., Oliveira, M.B.P.P., 2015. Are coffee silverskin extracts safe for topical use? An in vitro and in vivo approach. Ind. Crops Prod. 63, 167-174. https://doi.org/10. 1016/j.indcrop.2014.10.014.

Sahin, S.C., 2018. The potential of Arthrospira platensis extract as a tyrosinase inhibitor for pharmaceutical or cosmetic applications. South Afr. J. Bot. 119, 236-243. https:// doi.org/10.1016/j.sajb.2018.09.004.

Stanikunaite, R., Khan, Shabana I., Trappe, J.M., Ross, S.A., 2009. Cyclooxygenase-2 inhibitory and antioxidant compounds from the truffle elaphomyces granulatus. Phyther. Res. 23, 575-578. https://doi.org/10.1002/ptr.

Tachaprutinun, A., Meinke, M.C., Richter, H., Pan-In, P., Wanichwecharungruang, S., Knorr, F., Lademann, J., Patzelt, A., 2014. Comparison of the skin penetration of Garcinia mangostana extract in particulate and non-particulate form. Eur. J. Pharm. Biopharm. 86, 307-313. https://doi.org/10.1016/j.ejpb.2013.12.001.

Tamrakar, S., Nishida, M., Amen, Y., Tran, H.B., Suhara, H., Fukami, K., Parajuli, G.P., Shimizu, K., 2017. Antibacterial activity of Nepalese wild mushrooms against 
Staphylococcus aureus and Propionibacterium acnes. J. Wood Sci. 63, 379-387. https://doi.org/10.1007/s10086-017-1636-1.

Taofiq, O., Calhelha, R.C., Heleno, S., Barros, L., Martins, A., Santos-Buelga, C., Queiroz, M.J.R.P., Ferreira, I.C.F.R., 2015. The contribution of phenolic acids to the anti-inflammatory activity of mushrooms: screening in phenolic extracts, individual parent molecules and synthesized glucuronated and methylated derivatives. Food Res. Int. 76, 821-827. https://doi.org/10.1016/j.foodres.2015.07.044.

Taofiq, O., González-paramás, A.M., Barreiro, M.F., Ferreira, I.C.F.R., 2017a. Hydroxycinnamic acids and their Derivatives : cosmeceutical significance, challenges and future perspectives, a review. Molecules 22, 1-24. https://doi.org/10.3390/ molecules22020281.

Taofiq, O., González-Paramás, A.M., Martins, A., Barreiro, M.F., Ferreira, I.C.F.R., 2016a. Mushrooms extracts and compounds in cosmetics, cosmeceuticals and nutricosmetics-A review. Ind. Crops Prod. 90, 38-48. https://doi.org/10.1016/j. indcrop.2016.06.012.

Taofiq, O., Heleno, S., Calhelha, R., Alves, M., Barros, L., Barreiro, M., González-Paramás, A., Ferreira, I., 2016b. Development of mushroom-based cosmeceutical formulations with anti-inflammatory, anti-tyrosinase, antioxidant, and antibacterial properties.
Molecules 21, 1372. https://doi.org/10.3390/molecules21101372.

Taofiq, O., Heleno, S.A., Calhelha, R.C., Alves, M.J., Barros, L., González-Paramás, A.M., Barreiro, M.F., Ferreira, I.C.F.R., 2017b. The potential of Ganoderma lucidum extracts as bioactive ingredients in topical formulations, beyond its nutritional benefits. Food Chem. Toxicol. 108, 139-147. https://doi.org/10.1016/j.fct.2017.07.051.

Taofiq, O., Heleno, S.A., Calhelha, R.C., Fernandes, I.P., Alves, M.J., Barros, L., GonzálezParamás, A.M., Ferreira, I.C.F.R., Barreiro, M.F., 2018. Mushroom-based cosmeceutical ingredients: microencapsulation and in vitro release profile. Ind. Crops Prod. 124, 44-52. https://doi.org/10.1016/j.indcrop.2018.07.057.

Wang, H.M.D., Chen, C.C., Huynh, P., Chang, J.S., 2015. Exploring the potential of using algae in cosmetics. Bioresour. Technol. 184, 355-362. https://doi.org/10.1016/j. biortech.2014.12.001.

Wu, Y., Choi, M.-H., Li, J., Yang, H., Shin, H.-J., 2016. Mushroom cosmetics: the present and future. Cosmetics 3, 22. https://doi.org/10.3390/cosmetics3030022.

Žilius, M., Ramanauskiene, K., Briedis, V., 2013. Release of propolis phenolic acids from semisolid formulations and their penetration into the human skin in vitro. Evidencebased Complement. Altern. Med. 1-7. https://doi.org/10.1155/2013/958717. 